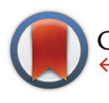

CrossMark

Cite this: Polym. Chem., 2017, 8, 431

\title{
A PHEA-g-PEO well-defined graft copolymer exhibiting the synchronous encapsulation of both hydrophobic pyrene and hydrophilic Rhodamine $6 \mathrm{G} \dagger$
}

\begin{abstract}
Fangxu Sun, Guolin Lu, Chun Feng, Yongjun Li and Xiaoyu Huang*
A well-defined graft copolymer consisting of a poly(2-hydroxyethyl acrylate) (PHEA) backbone and poly(ethylene oxide) (PEO) side chains was synthesized by successive reversible addition-fragmentation chain transfer (RAFT) polymerization and atom transfer nitroxide radical coupling (ATNRC) reaction. RAFT homopolymerization of a Cl-containing acrylate monomer, 2-hydroxyethyl 2-((2-chloropropanoyloxy) methyl)acrylate (HECPMA), was first performed in a controlled way to afford a well-defined PHEA-based backbone with a low polydispersity $\left(M_{w} / M_{n}=1.08\right)$. The target poly(2-hydroxyethyl acrylate)-gpoly(ethylene oxide) (PHEA-g-PEO) graft copolymer with a narrow molecular weight distribution $\left(M_{w} / M_{n}=\right.$ 1.16) was then obtained by ATNRC reaction between the pendant $-\mathrm{OCOCH}\left(\mathrm{CH}_{3}\right) \mathrm{Cl}$ group in every repeated unit of PHEA-based backbone and PEO with a TEMPO end group via the grafting-onto strategy, using CuCl/PMDETA as a catalytic system. The critical micelle concentrations (cmcs) of the obtained graft copolymer in pure water, brine, and aqueous $\mathrm{Na}_{2} \mathrm{SO}_{4}$ solution were determined by the fluorescence probe technique using $\mathrm{N}$-phenyl-1-naphthylamine as probe and micellar morphologies in aqueous media were visualized by TEM. It was found that PHEA-g-PEO graft copolymer self-assembled into large compound micelles in aqueous media, which can encapsulate hydrophilic Rhodamine 6G and hydrophobic pyrene separately or simultaneously.
\end{abstract}

Received 11th September 2016 Accepted 17th November 2016 DOI: $10.1039 / c 6 p y 01595 f$ www.rsc.org/polymers from $^{25,26}$ is a typical example of the combination of certain controlled polymerization approaches. The grafting-onto strategy is a promising way to construct graft copolymers because their structures and compositions can be tuned precisely. Thanks to the development of coupling reactions with high efficiency, this strategy has become a convenient and efficient way to synthesize graft copolymers. ${ }^{24,27,28}$

Click chemistry, ${ }^{29}$ in which Cu-catalyzed azide/alkyne cycloaddition (CuAAC) reaction has been studied most deeply, has been widely employed in polymer chemistry nowadays. ${ }^{29-32}$ However, the photosensitive and unstable azide compounds used in CuAAC would pose a security threat to people and need to be operated carefully. ${ }^{33}$

Combining NMRP and ATRP, Huang et al. put forward a new coupling strategy, atom transfer nitroxide radical coupling (ATNRC), ${ }^{33,34}$ in which graft copolymers can be obtained by the coupling reaction between the polymeric backbone containing halide atoms and the side chains containing 2,2,6,6tetramethylpiperidinyl-1-oxy (TEMPO) radicals in the presence of $\mathrm{CuBr}$ and ligands. ATNRC is quite different from ATRP because $\mathrm{CuBr}$ in ATNRC is not a catalyst, but a reactant. ${ }^{4,34}$ The carbon radicals on the backbone would be captured by TEMPO-containing polymeric chains immediately to form an 
alkoxyamine between two polymers. The coupling efficiency of ATNRC can be as high as $90 \%$, even comparable to CuAAC reaction, therefore ATNRC has been often employed as an efficient way to construct well-defined polymers, such as graft, star, and block copolymers. ${ }^{35-39}$

Poly(ethylene oxide) (PEO) is often chosen as the hydrophilic part of amphiphilic copolymers ${ }^{40-43}$ since PEO is a kind of nontoxic, nonionic, semi-crystalline polymer with excellent solubility in aqueous media. ${ }^{44}$ Besides, it also displays excellent chemical and biological properties including non-covalent complexation ability, good biocompatibility, lack of immunogenicity, and resistance to both protein adsorption and cellular adhesion. ${ }^{4-48}$ Particularly, the incorporation of a PEO segment into a macromolecule can obviously modulate the properties of polymeric solution. ${ }^{49}$ ATNRC is a convenient way to graft PEO side chains to the polymeric backbone because well-defined PEO homopolymers with defined terminal functionalities are commercially available. ${ }^{33,50}$ Graft copolymers bearing PEO side chains have been obtained via ATNRC effectively with a tunable density of PEO side chains. ${ }^{33,51-54}$

As for graft copolymers based on poly(2-hydroxyethyl acrylate) (PHEA)/poly(2-hydroxyethyl methylacrylate) (PHEMA) as the polymeric backbone, their synthesis is a tough task because the pendant hydroxyls are usually utilized to connect the side chains via ring opening polymerization (ROP), ${ }^{55}$
ATRP $^{56-58}$ or "click chemistry", ${ }^{24}$ etc. In addition, PHEMA has always been regarded as one kind of hydrophilic copolymers. In 2004, however, Armes et al. discovered that the solubility of PHEMA-based copolymers was closely related with polymerization degree, temperature, and composition. ${ }^{59}$ Thus, an interesting question arises from those studies, what would be the self-assembly behavior in aqueous phase of the graft copolymers bearing PHEA/PHEMA as the backbone and PEO as the side chains?

On the basis of a newly developed trifunctional monomer, 2-hydroxyethyl 2-((2-chloropropanoyloxy)methyl)acrylate (HECPMA) bearing a -OCOCH$\left(\mathrm{CH}_{3}\right) \mathrm{Cl}$ moiety and a hydroxyl simultaneously, ${ }^{60}$ the pendant hydroxyls can remain intact while grafting the side chains. Herein, we report the synthesis of a poly(2-hydroxyethyl acrylate)- $g$-poly(ethylene oxide) (PHEA- $g$ PEO) graft copolymer, bearing a PHEA backbone via ATNRC (Scheme 1). PHECPMA homopolymer with a pendant halogencontaining - $\mathrm{OCOCH}\left(\mathrm{CH}_{3}\right) \mathrm{Cl}$ group in every repeated unit was first obtained through RAFT homopolymerization of HECPMA monomer. PEO homopolymer with TEMPO terminal functionality was then grafted onto PHECPMA backbone by ATNRC to give the well-defined PHEA-g-PEO graft copolymer. Interestingly, PHEA- $g$-PEO graft copolymer could self-assemble in aqueous media to form large compound micelles, able to encapsulate hydrophobic and hydrophilic agents.

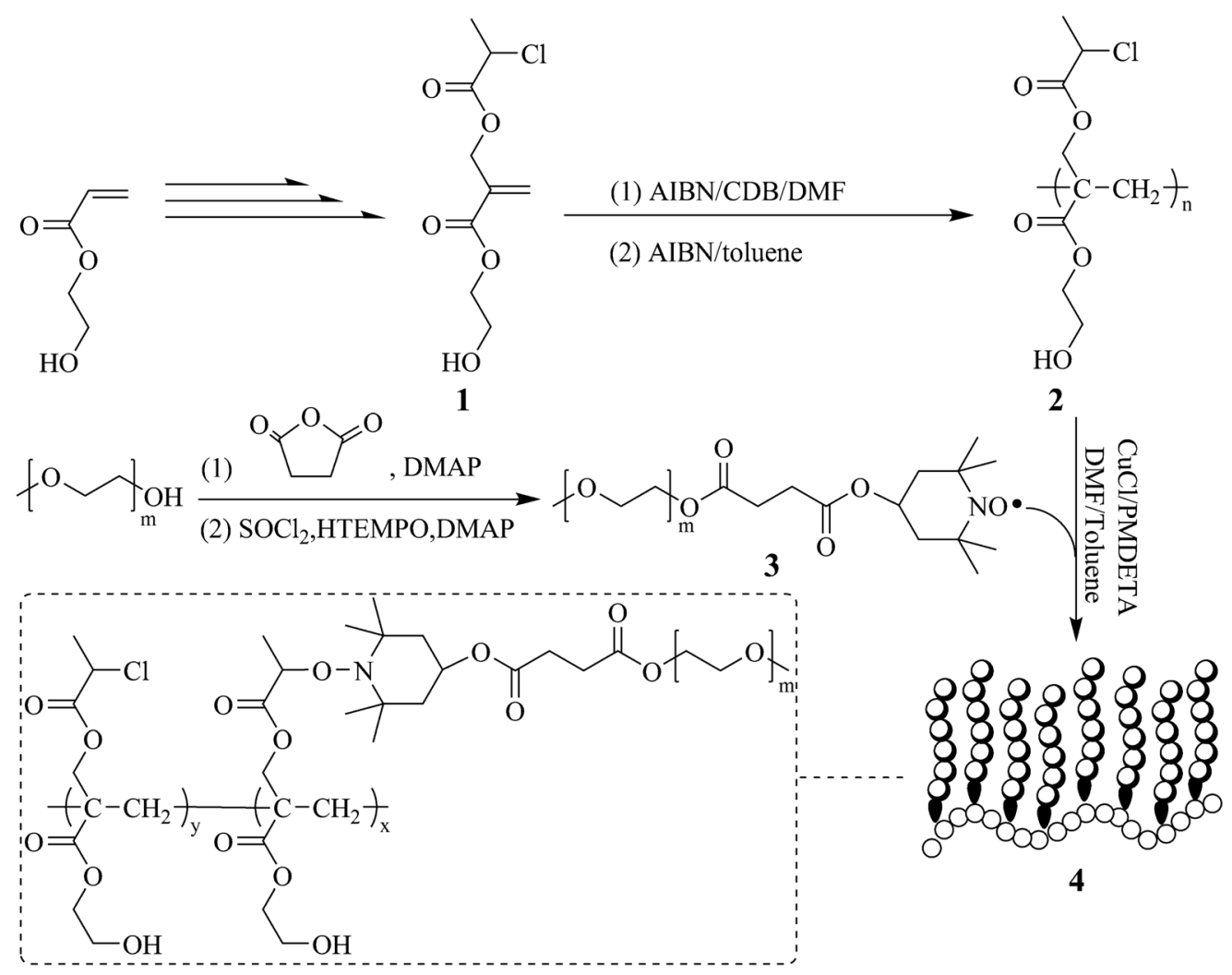

Scheme 1 Synthetic route of PHEA-g-PEO well-defined graft copolymer. 


\section{Results and discussion}

\section{Preparation of PHEA-based well-defined backbone}

It has been extensively reported that ethylene oxide, a cyclic monomer, cannot be polymerized via RDRP, which means that graft copolymers bearing PEO side chains cannot be constructed through the most popular grafting-from approach using RDRP. On the other hand, well-defined PEO homopolymers with precisely determined molecular weights, narrow molecular weight distributions, and controllable end functionalities are commercially available so that the graftingonto strategy using the coupling reactions with high efficiency such as click chemistry and ATNRC is generally used for constructing graft copolymers with PEO side chains. $^{24,33,52-54}$

In the current case, the desired graft copolymer is PHEA-gPEO in which every repeated unit of the backbone possesses a pendant hydroxyl, that is to say PEO side chains cannot be attached onto the backbone through the usual ester linkage. To solve this puzzle, HECPMA monomer ${ }^{60}$ developed by us in 2014 which comprised a polymerizable double bond, a halogen-containing -OCOCH$\left(\mathrm{CH}_{3}\right) \mathrm{Cl}$ group, and a hydroxyl was herein employed. The first amphiphilic graft copolymer containing a hydrophilic PHEA backbone, PHEA-g-PS, was obtained through the grafting-from strategy ${ }^{60}$ via ATRP of styrene initiated by $-\mathrm{OCOCH}\left(\mathrm{CH}_{3}\right) \mathrm{Cl}$ group in every repeated unit of PHECPMA homopolymer; and this graft copolymer is quite different from PHEMA/PHEA-based graft copolymers $^{24,55-58}$ whose backbone was usually hydrophobic because the pendant hydroxyls of the backbone were utilized for connecting the side chains. Moreover, halide $(\mathrm{Cl})$ atom of -OCOCH$\left(\mathrm{CH}_{3}\right) \mathrm{Cl}$ group in every repeated unit of PHECPMA homopolymer can also be an effective component in ATNRC reaction so as to be treated with terminal TEMPO radical of the polymeric chain for affording the corresponding graft copolymer through the grafting-onto strategy. Herein, we assume that PHEA-g-PEO graft copolymer can be formed via ATNRC reaction between $\mathrm{Cl}$ atom of $-\mathrm{OCOCH}\left(\mathrm{CH}_{3}\right) \mathrm{Cl}$ group in every repeated unit of PHECPMA backbone and TEMPO end functionality of PEO side chains.

Firstly, a well-defined PHEA-based backbone possessing a pendant hydroxyl in every repeated unit was constructed via RAFT homopolymerization of HECMPA 1 monomer using $\mathrm{CDB}^{61}$ as chain transfer agent (CTA). ATRP is not suitable for the homopolymerization of HECPMA because ATRP of functional monomers comprising a halogen-containing initiating group would result in an undesirable hyperbranched polymer, not a linear polymer. $^{62}$ RAFT polymerization with excellent tolerance of various functionalities ${ }^{63,64}$ was employed for the homopolymerization of HECPMA monomer since it would not interfere with $-\mathrm{OCOCH}\left(\mathrm{CH}_{3}\right) \mathrm{Cl}$ group during the polymerization process. As HECPMA is an acrylate monomer, CDB might be the appropriate CTA for its RAFT homopolymerization. ${ }^{65}$ A pink powder with dithiobenzoate end group (inset a in Fig. 1) was first obtained, which would pose a negative influence on the following ATNRC reaction.

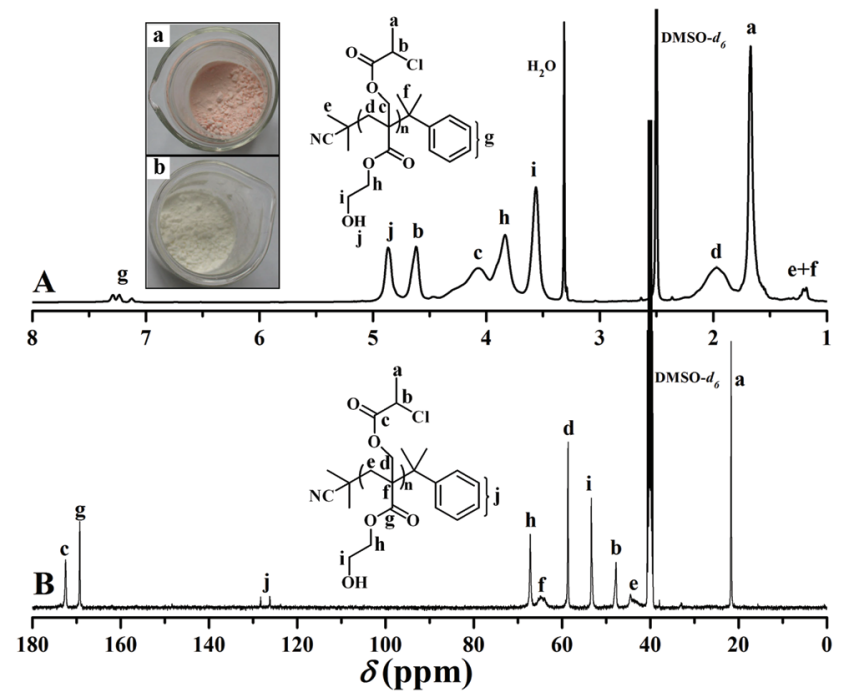

Fig. $1{ }^{1} \mathrm{H}(\mathrm{A})$ and ${ }^{13} \mathrm{C}(\mathrm{B})$ NMR spectra of PHECPMA 2 in DMSO- $d_{6}$.

Then, excessive AIBN (32.9 eq.) was used to eliminate the terminal dithiobenzoate group, ${ }^{66}$ affording a white PHECPMA 2 homopolymer (inset b in Fig. 1) and the disappearance of the signal of dithiobenzoate end group at $510 \mathrm{~nm}$ in UV/vis absorbance spectrum showed the complete removal of dithiobenzoate end group. ${ }^{66}$

PHECPMA 2 homopolymer was characterized by GPC, FT-IR, ${ }^{1} \mathrm{H}$ NMR, and ${ }^{13} \mathrm{C}$ NMR and the details can be found in our previous report. ${ }^{60}$ In particular, ${ }^{1} \mathrm{H}$ NMR spectrum of the homopolymer (Fig. 1A) exhibited the absence of the signals of the double bond of HECPMA monomer at 5.95 and $6.46 \mathrm{ppm}$, which closely matched the disappearance of the peaks at 129.0 and $134.4 \mathrm{ppm}$ in ${ }^{13} \mathrm{C}$ NMR spectrum (Fig. 1B), verifying the successful polymerization of HECPMA monomer. RAFT mechanism of the polymerization was illustrated by the multiplet between $7.11 \mathrm{ppm}$ and $7.30 \mathrm{ppm}$ in ${ }^{1} \mathrm{H}$ NMR spectrum plus the peaks at 126.0 and $128.1 \mathrm{ppm}$ in ${ }^{13} \mathrm{C}$ NMR spectrum belonged to the phenyl end group. The proton resonance signals of the $-\mathrm{OCOCH}\left(\mathrm{CH}_{3}\right) \mathrm{Cl}$ group were located at 4.63 and $1.66 \mathrm{ppm}$ and the corresponding carbon resonance signals were located at $21.8\left(\mathrm{CHClCH}_{3}\right)$ and 47.8 $\left(\mathrm{CHClCH}_{3}\right) \mathrm{ppm}$, respectively, which confirmed the retention of $-\mathrm{OCOCH}\left(\mathrm{CH}_{3}\right) \mathrm{Cl}$ group during RAFT polymerization and the elimination of terminal dithiobenzoate group. The proton resonance signal of hydroxyl also appeared at $4.88 \mathrm{ppm}$ in Fig. 1A. Thus, all these evidences clearly witnessed the formation of a well-defined PHECPMA 2 homopolymer bearing a pendant - $\mathrm{OCOCH}\left(\mathrm{CH}_{3}\right) \mathrm{Cl}$ group and hydroxyl in every repeated unit. Moreover, because every HECPMA repeated unit consists of both a hydrophilic hydroxyl and hydrophobic -OCOCH $\left(\mathrm{CH}_{3}\right) \mathrm{Cl}$ moiety, PHECPMA 2 homopolymer may behave like a kind of amphiphilic homopolymer. ${ }^{67}$ Indeed, this homopolymer is water-soluble with low solubility and it self-assembled into aggregates with a hydrodynamic diameter $\left(D_{\mathrm{h}}\right)$ of about $80 \mathrm{~nm}$ with the rising of the concentration of the homopolymer in aqueous media. 
The absolute molecular weight of the homopolymer ( $\left.M_{\mathrm{n}, \mathrm{GPC} / \mathrm{MALS}}\right)$ was determined by GPC/MALS with a value of $8223 \mathrm{~g} \mathrm{~mol}^{-1}$ so that the number of HECPMA repeated unit was calculated according to eqn (1) (187 and 236.5 refer to the molecular weights of terminal CTA moiety and HECPMA monomer, respectively). The result showed that PHECPMA 2 homopolymer possesses $34.0-\mathrm{OCOCH}\left(\mathrm{CH}_{3}\right) \mathrm{Cl}$ groups.

$$
n_{\mathrm{HECPMA}}=\left(M_{\mathrm{n}, \mathrm{GPC} / \mathrm{MALS}}-187\right) / 236.5
$$

\section{Characterization of PEO-TEMPO}

Commercially available PEO-OH $\left(M_{\mathrm{n}}=2000 \mathrm{~g} \mathrm{~mol} \mathrm{~m}^{-1}\right)$ was firstly converted to $\mathrm{PEO}-\mathrm{COOH}$ through the esterification of terminal hydroxyl using succinic anhydride. The broad peak at $3507 \mathrm{~cm}^{-1}$ and the sharp band at $1734 \mathrm{~cm}^{-1}$ in FT-IR spectrum after the esterification (Fig. 2A) were attributed to the newly incorporated carboxyl, and the peaks located at 2.60, 3.55, and $4.21 \mathrm{ppm}$ in ${ }^{1} \mathrm{H}$ NMR spectrum belonged to the protons of the linkage between PEO and carboxyl, which evidenced that the terminal hydroxyl of PEO had been transformed into carboxyl. Furthermore, the signal at $173.9 \mathrm{ppm}$ in ${ }^{13} \mathrm{C}$ NMR spectrum also distinctly affirmed the introduction of carboxyl.

Next, treated with $\mathrm{SOCl}_{2}, \mathrm{PEO}-\mathrm{COOH}$ was converted to PEO-COCl almost quantitatively followed by its in situ reaction with HTEMPO to afford the desired PEO-TEMPO. The color change from colorless to orange was the first piece of evidence on the demonstration of successful preparation of PEO-TEMPO. In FT-IR spectrum (Fig. 2B), the disappearance of the broad peak at $3507 \mathrm{~cm}^{-1}$ pointed out the complete conversion of carboxyl. Meanwhile, the resonance signals at 1.15, 1.53, and 1.85 ppm in ${ }^{1} \mathrm{H}$ NMR spectrum (Fig. 3A) were attributed to the protons of $\mathrm{CH}_{3}$ and $\mathrm{CH}_{2}$ of TEMPO moiety, and the peaks at $19.9\left(\mathrm{CH}_{3}\right)$ and $60.9\left(\mathrm{C}\left(\mathrm{CH}_{3}\right)_{2}\right) \mathrm{ppm}$ in ${ }^{13} \mathrm{C}$ NMR spectrum (Fig. 3B) also verified the incorporation of TEMPO. The covalent connection between TEMPO and PEO

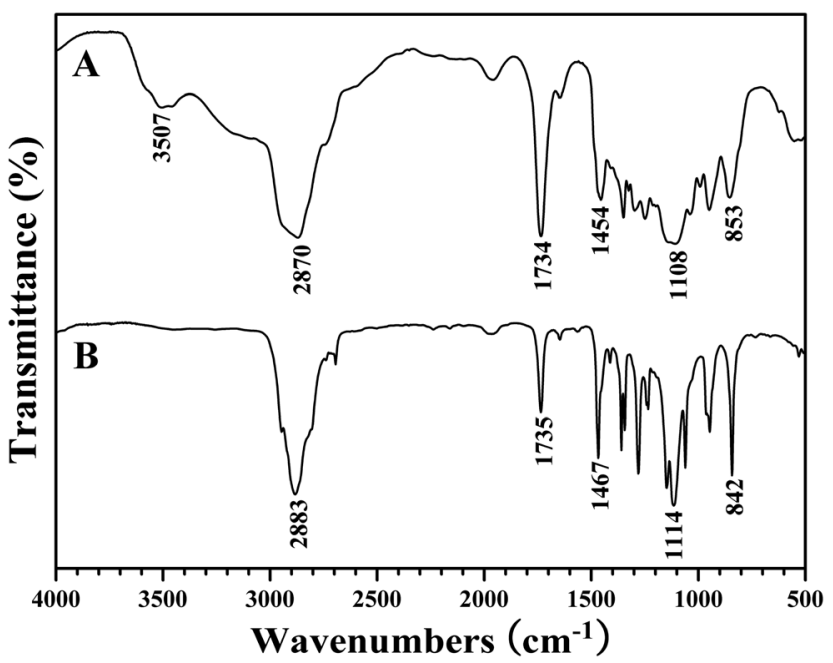

Fig. 2 FT-IR spectra of PEO-COOH (A) and PEO-TEMPO (B).

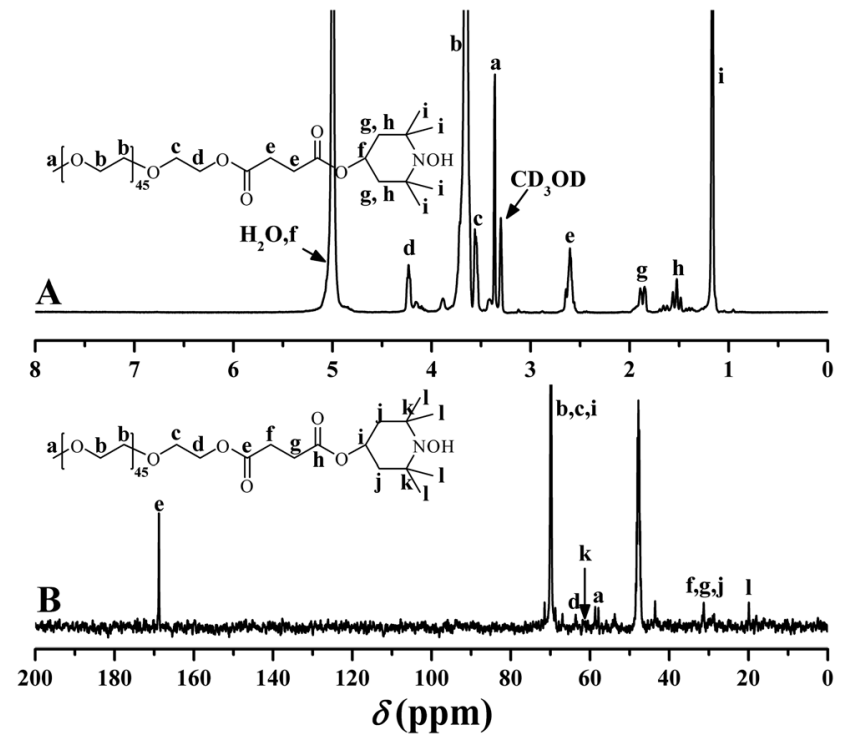

Fig. $3{ }^{1} \mathrm{H}(\mathrm{A})$ and ${ }^{13} \mathrm{C}$ (B) NMR spectra of PEO-TEMPO 3 in $\mathrm{CD}_{3} \mathrm{OD}$.

was demonstrated by the peak at $2.60 \mathrm{ppm}$ originating from 4 protons of $\mathrm{CO}_{2} \mathrm{CH}_{2} \mathrm{CH}_{2} \mathrm{CO}_{2}$. Thus, it is clear that PEO was successfully functionalized with TEMPO end group, giving PEO-TEMPO 3.

\section{Synthesis of PHEA- $g$-PEO well-defined graft copolymer}

The desired PHEA-g-PEO graft copolymer was constructed via the grafting-onto strategy by a $\mathrm{Cu}(\mathrm{I})$-mediated ATNRC reaction since the pendant $-\mathrm{OCOCH}\left(\mathrm{CH}_{3}\right) \mathrm{Cl}$ groups in PHECPMA 2 were designed to directly couple with the terminal TEMPO functionality of PEO-TEMPO 3. Herein, ATNRC reaction ${ }^{23,33-39}$ was performed in DMF/toluene ( $\mathrm{v}: \mathrm{v}=1: 1)$ at $90{ }^{\circ} \mathrm{C}$ using $\mathrm{CuCl} / \mathrm{PDMAEA}$ as catalytic system and the results are summarized in Table 1. Dialysis was utilized to exclude the unreacted PEO-TEMPO 3 as affirmed by GPC curve after purification (Fig. 4) where the trace of PEO-TEMPO 3 was absent. The molecular weight of the purified product was much higher than that of PHECPMA, which demonstrated the occurrence of a coupling reaction. Moreover, it should be pointed out that GPC curve showed a unimodal and symmetric eluent peak without tailing or shoulder, this

Table 1 Synthesis of PHEA-g-PEO 4 graft copolymer ${ }^{a}$

\begin{tabular}{lllll}
\hline$[\mathrm{TEMPO}]:[\mathrm{CuCl}]$ & $M_{\mathrm{n}, \mathrm{GPC}}{ }^{b}\left(\mathrm{~g} \mathrm{~mol}^{-1}\right)$ & $M_{\mathrm{w}} / M_{\mathrm{n}}{ }^{b}$ & $n_{\mathrm{PEO}}{ }^{c}$ & $\left.D_{\mathrm{graft}^{d}}{ }^{d} \%\right)$ \\
\hline $1.2: 1$ & 41900 & 1.16 & 11.0 & 32.4
\end{tabular}

${ }^{a}$ Synthesized from PHECPMA $2\left(M_{\mathrm{n}, \mathrm{GPC} / \mathrm{MALS}}=8223 \mathrm{~g} \mathrm{~mol}{ }^{-1}, M_{\mathrm{w}} / M_{\mathrm{n}}=\right.$ 1.08, $\left.N_{\text {HECPMA }}=34.0\right)$ and PEO-TEMPO 3 in DMF/toluene $(\mathrm{v}: \mathrm{v}=1: 1)$ using CuCl/PMDETA, [PMDETA]:[CuCl] $=1: 1$, temperature: $90{ }^{\circ} \mathrm{C}$, time: 3 h. ${ }^{b}$ Measured by GPC in DMF at $35^{\circ} \mathrm{C} .{ }^{c}$ The number of grafted PEO side chains obtained from ${ }^{1} \mathrm{H}$ NMR. ${ }^{d}$ The grafting density of PEO side chain obtained from ${ }^{1} \mathrm{H}$ NMR. 


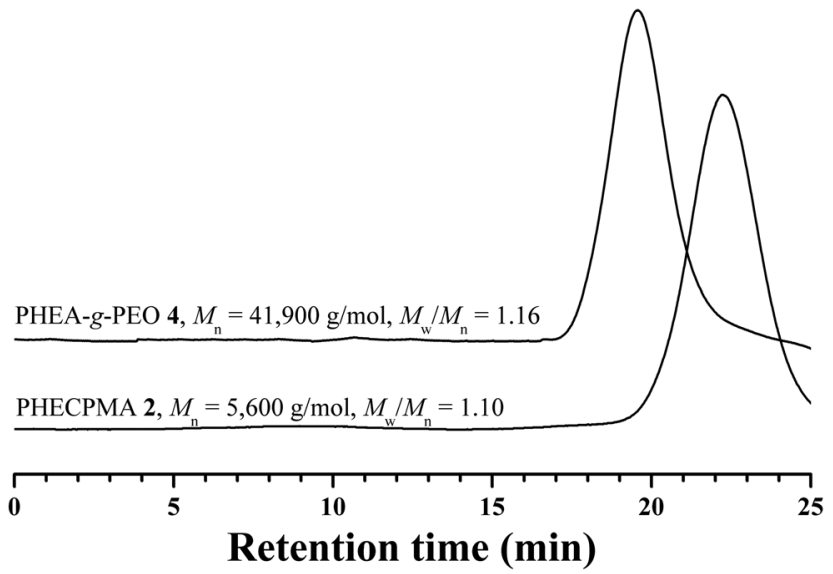

Fig. 4 GPC curves of PHECPMA 2 and PHEA-g-PEO 4 in DMF.

indicating the absence of intra- or inter-termination during the coupling process; ${ }^{68}$ and the polydispersity was as low as 1.16, which illustrated that the structure of the product was well-defined.

${ }^{1} \mathrm{H}$ NMR spectrum of the purified product in $\mathrm{CDCl}_{3}$ is shown in Fig. 5A. The peaks appearing at $2.62(4 \mathrm{H}$, $\left.\mathrm{O}_{2} \mathrm{CCH}_{2} \mathrm{CH}_{2} \mathrm{CO}_{2}\right), 3.38\left(3 \mathrm{H}, \mathrm{OCH}_{3}\right), 3.56\left(2 \mathrm{H}, \mathrm{CO}_{2} \mathrm{CH}_{2} \mathrm{CH}_{2} \mathrm{O}\right)$, $3.64\left(4 \mathrm{H}, \mathrm{OCH}_{2} \mathrm{CH}_{2}\right)$, and $4.25\left(2 \mathrm{H}, \mathrm{CO}_{2} \mathrm{CH}_{2} \mathrm{CH}_{2} \mathrm{O}\right)$ ppm were typical proton resonance signals of $\mathrm{PEO}$ side chains while the proton resonance signal originating from the polyacrylatebased backbone was located at $2.06\left(2 \mathrm{H}, \mathrm{CH}_{2} \mathrm{CCO}_{2}\right) \mathrm{ppm}$. The presence of a piperidine linkage between PHEA backbone and PEO side chains was clearly evidenced by the proton resonance signals at $0.89,1.21\left(12 \mathrm{H}, \mathrm{CH}_{3}\right.$ of TEMPO), 1.25, 1.38 $\left(4 \mathrm{H}, \mathrm{CH}_{2}\right.$ of TEMPO), and $5.00(1 \mathrm{H}, \mathrm{CH}$ of TEMPO) ppm. The minor peak at $3.88\left(2 \mathrm{H}, \mathrm{CO}_{2} \mathrm{CH}_{2} \mathrm{CH}_{2} \mathrm{OH}\right)$ ppm plus the strong peak at $3430 \mathrm{~cm}^{-1}$ in FT-IR spectrum verified the retention

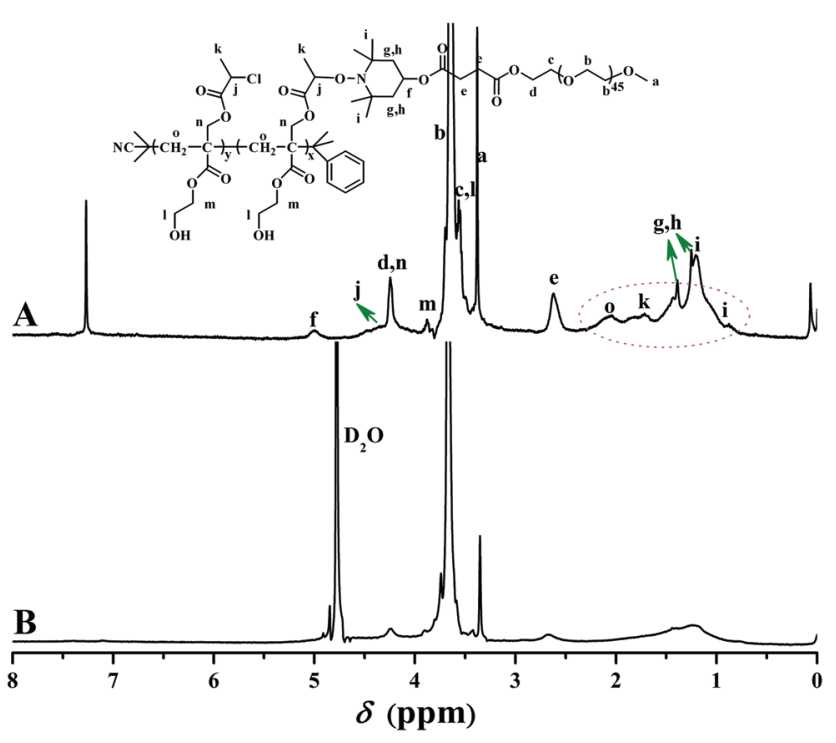

Fig. $5{ }^{1} \mathrm{H}$ NMR spectra of PHEA-g-PEO 4 in $\mathrm{CDCl}_{3}(\mathrm{~A})$ and $\mathrm{D}_{2} \mathrm{O}(\mathrm{B})$. of pendant hydroxyls in the polyacrylate-based backbone after ATNRC reaction, i.e. hydroxyl is inert during the $\mathrm{Cu}(\mathrm{I})$ mediated coupling reaction.

For graft copolymers with a non-linear structure, molecular weight, which is the basis for the calculation of the number of side chains, measured by GPC using linear polystyrene as standard, is certainly much different from the 'actual' value according to previous reports. ${ }^{21,69,70}$ Therefore, the number of grafted PEO side chains of PHEA- $g$-PEO 4 graft copolymer $\left(n_{\mathrm{PEO}}\right)$, which was built through the grafting-onto approach, was estimated by ${ }^{1} \mathrm{H}$ NMR instead of conventional GPC according to eqn (2) $\left(S_{\mathrm{e}}\right.$ and $S_{\mathrm{m}}$ are the integrated areas of peaks "e" at $2.62 \mathrm{ppm}$ and "m" at $3.88 \mathrm{ppm}$ in Fig. 5A, 34 is the number of HECPMA repeated units in the backbone). The result is 11.0 as listed in Table 1 so that the grafting density of PEO side chain was calculated to be $32.4 \%$ according to eqn (3). This grafting efficiency was similar to the moderate coupling efficiencies (36-75\%) of CuAAC "grafting-onto" reaction. ${ }^{71}$ The relatively low coupling efficiency in the current work could be attributed to the steric hindrance of the dense structure of the graft copolymer. ${ }^{34,71}$ Thus, it is clear that PHEA- $g$-PEO 4 graft copolymer possesses a well-defined structure: a poly(2hydroxyethyl acrylate) backbone (34.0 repeated units) and 11.0 grafted PEO side chains of a certain length (44.8 repeated units per side chain).

$$
\begin{gathered}
n_{\mathrm{PEO}}=34 S_{\mathrm{e}} / 2 S_{\mathrm{m}} \\
D_{\text {graft }}=n_{\mathrm{PEO}} / 34
\end{gathered}
$$

\section{Self-assembly of PHEA-g-PEO graft copolymer}

In 2004, Armes et al. systematically investigated the solubility of copolymers based on PHEMA and they found that it was associated with molecular weight, composition, and temperature, ${ }^{59}$ which meant that the backbone of PHEA- $g$-PEO 4 graft copolymer, PHEA, was not absolutely water-soluble. As it was mentioned before that PHECPMA 2 homopolymer behaves like a kind of amphiphilic homopolymer, and only one third of hydrophobic - $\mathrm{OCOCH}\left(\mathrm{CH}_{3}\right) \mathrm{Cl}$ moiety was consumed for coupling, we can deduce that PHEA backbone with 22.4 hydrophobic-OCOCH$\left(\mathrm{CH}_{3}\right) \mathrm{Cl}$ groups may act as a hydrophobic core in aqueous media, which offers an opportunity for studying the self-assembly behavior in aqueous media.

First of all, critical micelle concentrations (cmcs) of PHEA$g$-PEO 4 graft copolymer in aqueous media and different salt solutions $\left([\mathrm{NaCl}]=0.2\right.$ and $0.8 \mathrm{~mol} \mathrm{~L}^{-1},\left[\mathrm{Na}_{2} \mathrm{SO}_{4}\right]=$ $0.3 \mathrm{~mol} \mathrm{~L}^{-1}$ ) were measured by fluorescence spectroscopy using PNA as probe (Fig. 6). The fluorescence spectrum of PNA is sensitively influenced by the environment and the polarity of its surrounding. ${ }^{72,73}$ In the presence of micelles, PNA can be solubilized within the interior of the hydrophobic part so that the fluorescence intensity will increase with the ascending of the concentration of polymer. Fig. 6A shows the relationship of the fluorescence intensity of PNA $\left(I / I_{0}\right)$ with the concentration of PHEA-g-PEO 4 graft copolymer in aqueous media. Apparently, $I / I_{0}$ rose sharply while the con- 

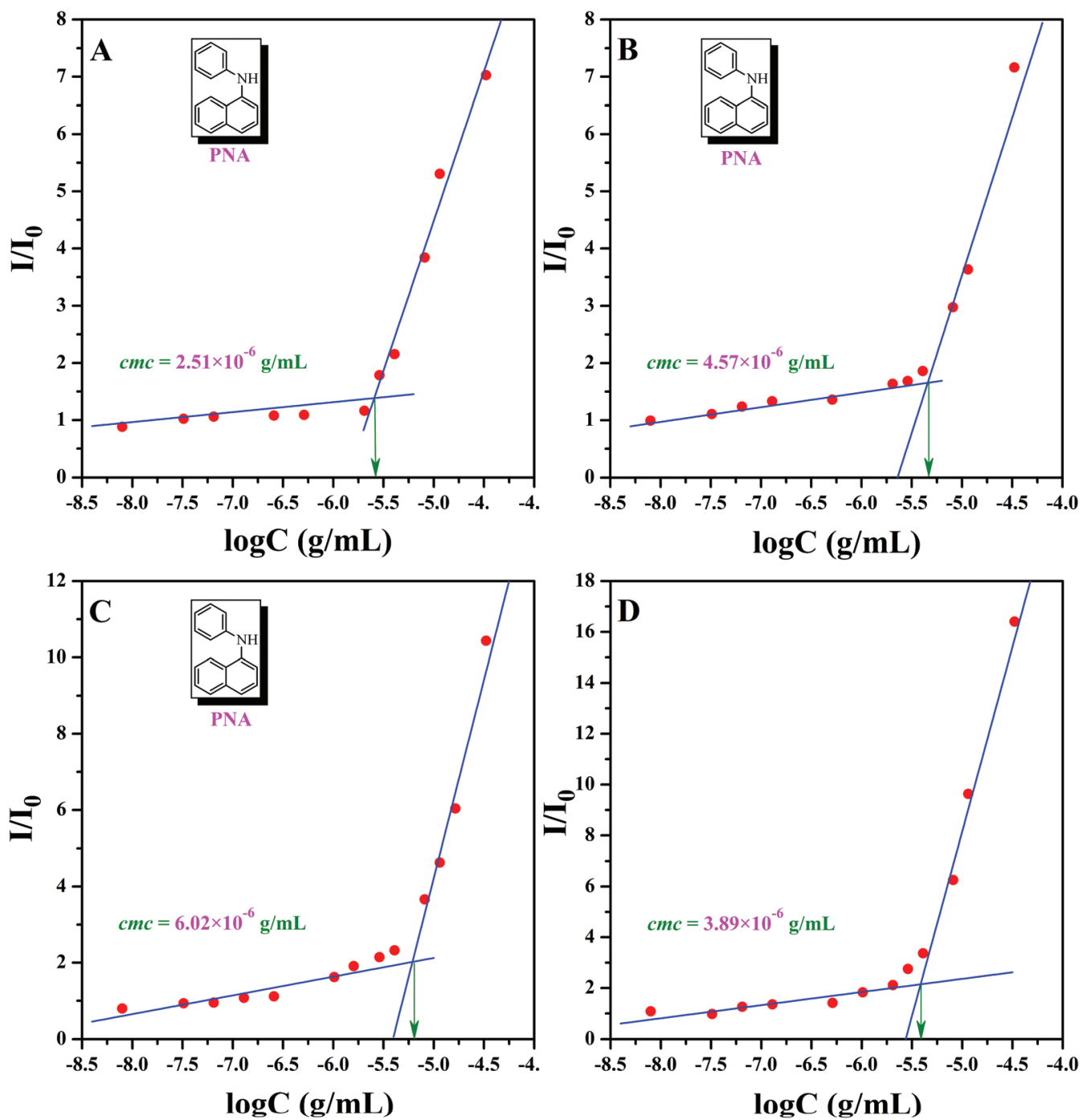

Fig. 6 Dependence of fluorescence intensity ratio of PNA emission band at $418 \mathrm{~nm}$ ([PNA] $=2 \times 10^{-6} \mathrm{~g} \mathrm{~mL}^{-1}$ ) on the concentration of PHEA- $g$-PEO 4 graft copolymer in pure water (A), $0.2 \mathrm{M} \mathrm{NaCl}$ (B), $0.8 \mathrm{M} \mathrm{NaCl}(\mathrm{C})$, and $0.3 \mathrm{M} \mathrm{Na}_{2} \mathrm{SO}_{4}$ (D).

centration of PHEA- $g$-PEO 4 graft copolymer exceeded a certain value, this indicating the incorporation of PNA probe into the hydrophobic core of micelles. ${ }^{72}$ Thus, cmc of PHEA-g-PEO 4 graft copolymer in aqueous media was determined to be the intersection of two straight lines with a value of $2.51 \times 10^{-6} \mathrm{~g} \mathrm{~mL}{ }^{-1}$. As shown in Fig. 6B-D, cmcs of PHEA-g-PEO 4 graft copolymer in different salt solutions are all higher than that in pure water, especially for two brine solutions $\left(4.57 \times 10^{-6} \mathrm{~g} \mathrm{~mL}^{-1}\right.$ for $[\mathrm{NaCl}]=0.2 \mathrm{M}$ and $6.02 \times 10^{-6}$ $\mathrm{g} \mathrm{mL} \mathrm{m}^{-1}$ for $\left.[\mathrm{NaCl}]=0.8 \mathrm{M}\right)$, which shows that cmc of PHEA- $g$ PEO 4 graft copolymer could be affected by adding an inorganic salt to increase the ion strength of solution. This effect might impact the hydrophobic segment to make the $\mathrm{cmc}$ rise or drop. In addition, all four cmcs are much lower than those of low molecular weight surfactants; however, they are comparable to those of polymeric amphiphiles. ${ }^{74,75}$

Aqueous and salt solutions of PHEA- $g$-PEO 4 graft copolymer with a concentration of $0.1 \mathrm{mg} \mathrm{mL}^{-1}$ (above $\mathrm{cmc}$ ) were then prepared for TEM and DLS measurements. Micellar morphologies were visualized under TEM and it can be seen from Fig. 7 that PHEA-g-PEO 4 graft copolymer aggregated into spherical micelles in both pure water and salt solutions, whose sizes were distributed between $145.0 \mathrm{~nm}$ and $187.0 \mathrm{~nm}$ as determined by DLS in various aqueous media as shown in Fig. 8. Particularly, the micellar size in pure water was larger than those in salt solutions, which also evidenced that salt had an influence on the self-assembly behavior of PHEA- $g$ PEO 4 graft copolymer in aqueous media. The chemical composition of the micelles formed by PHEA- $g$-PEO 4 graft copolymer in aqueous media, i.e. the building segment of the core and corona, was determined by ${ }^{1} \mathrm{H}$ NMR in $\mathrm{D}_{2} \mathrm{O} .{ }^{1} \mathrm{H}$ NMR is a common and convenient way to observe the solubility of a copolymer since the proton resonance signals of the insoluble segment would decrease significantly, even disappear, while the proton resonance signals of the soluble segment would remain unchanged. It can be seen from Fig. 5B that the 


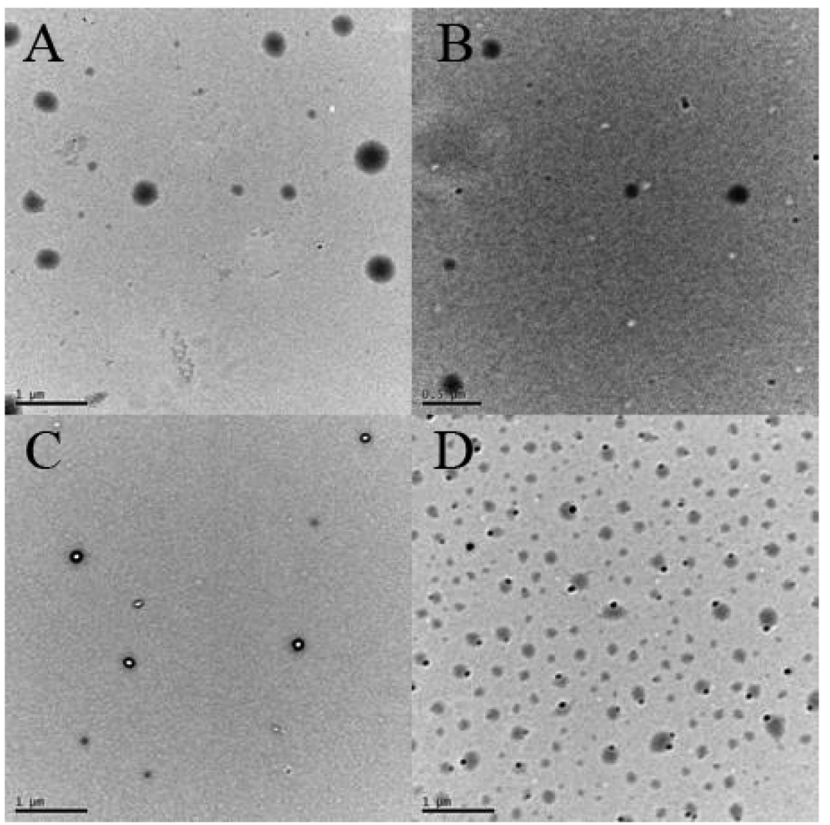

Fig. 7 TEM images of micelles formed by PHEA-g-PEO 4 graft copolymer in pure water (A), $0.2 \mathrm{M} \mathrm{NaCl}$ (B), $0.8 \mathrm{M} \mathrm{NaCl}$ (C), and $0.3 \mathrm{M}$ $\mathrm{Na}_{2} \mathrm{SO}_{4}$ (D) with a concentration of $0.1 \mathrm{mg} \mathrm{mL}^{-1}$.

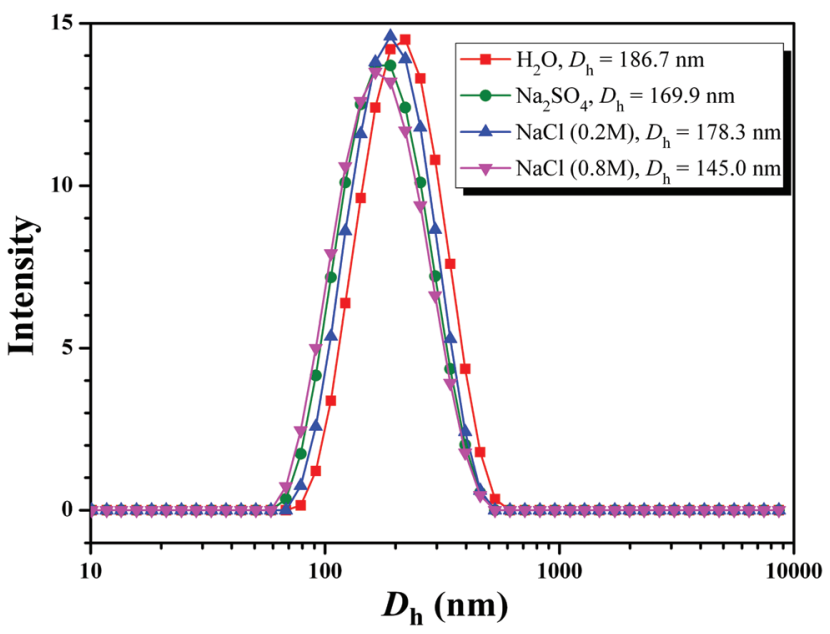

Fig. 8 Hydrodynamic diameter distributions of PHEA-g-PEO 4 graft copolymer in various solutions with a concentration of $0.1 \mathrm{mg} \mathrm{mL}^{-1}$.

characteristic proton resonance signals corresponding to PHEA backbone including peaks "j", "k", " $\mathrm{m}$ ", and "o" became attenuated apparently compared to those in Fig. 5A, however the typical proton resonance signals originating from PEO side chains such as peaks "a", "b", and "c" did not change at all. This result clearly supported our deduction that PHEA backbone with 22.4 hydrophobic $-\mathrm{OCOCH}\left(\mathrm{CH}_{3}\right) \mathrm{Cl}$ groups acted as hydrophobic core and PEO side chains acted as hydrophilic corona in the current case; in contrast, PHEA backbone possessing pendent hydroxyls (all $-\mathrm{OCOCH}\left(\mathrm{CH}_{3}\right) \mathrm{Cl}$ groups were consumed for initiation) acted as hydrophilic corona and PS side chains acted as hydrophobic core for PHEA-g-PS amphiphilic graft copolymer reported in $2014 .^{60}$

Given the fact that the total lengths of PEG side chain and PHEA backbone were much smaller than half of $D_{\mathrm{h}}$, these observations indicated that large compound micelles, not usual spherical micelles, were supposed to be formed in aqueous media, where PEO side chains formed the corona of micelles and the core consisted of numerous reverse micelles with islands of PEO segments in the continuous phase of PHEA segments. ${ }^{76,77}$

For common spherical micelles with a hydrophobic core and hydrophilic corona, only hydrophobic compounds can be encapsulated within the core of micelles. Nevertheless, according to the aforementioned results, PHEA-g-PEO 4 graft copolymer aggregated into large compound micelles in aqueous media so that it can be supposed that the hydrophilic and hydrophobic domains within the core of large compound micelles might be able to encapsulate both hydrophobic and hydrophilic agents. Therefore, pyrene soluble in the hydrophobic domain and water-soluble Rhodamine 6G (R6G) were employed as model guest molecules for examining the encapsulating ability of large compound micelles formed by PHEA-g-PEO 4 graft copolymer. We firstly checked the encapsulation capacity of aqueous micellar solution of copolymer $\mathbf{4}$ for hydrophobic compound in aqueous media using pyrene as a model hydrophobic agent ${ }^{78}$ and the loading content of pyrene, $9.7 \mu \mathrm{g}$ pyrene per $\mathrm{mg}$ micelle, was determined by UV/ vis absorption spectroscopy using a standard curve at $337 \mathrm{~nm}$. The aqueous solution of pyrene (after filtration to remove the insoluble pyrene) showed almost no UV absorption of pyrene (Fig. 9A) while the typical UV absorption of pyrene appeared at $337 \mathrm{~nm}$ in UV/vis absorption spectrum of aqueous micellar solution of copolymer 4 (Fig. 9A), which illustrated that micelles could sequester pyrene from water so as to solubilize pyrene within the hydrophobic domains of the core. ${ }^{79,80}$

Next, R6G was used as a model hydrophilic agent to check the encapsulation ability of aqueous micellar solution of copolymer 4 for hydrophilic compound. The loading content of R6G, $3.68 \mu \mathrm{g}$ R6G per mg micelle, was also determined by UV/vis absorption spectroscopy using a standard curve at $522 \mathrm{~nm}$. To check whether the amine group of R6G reacted with the pendant $\mathrm{Cl}$ in the graft copolymer, we recovered the graft copolymer from the micellar solution after loading with R6G by lyophilization and performed GPC measurement of the obtained graft copolymer using a UV detector $(522 \mathrm{~nm})$. Indeed, there is no detectable signal at $522 \mathrm{~nm}$, the maximum absorbance for R6G, which meant that no R6G was covalently attached to the graft copolymer via a reaction between amine group of R6G and $\mathrm{Cl}$ of graft copolymer. The characteristic absorption peak of R6G was located at $522 \mathrm{~nm}$ in UV/vis absorption spectrum of R6G-containing aqueous micellar solution of copolymer $\mathbf{4}$ (after dialysis to remove free R6G) as shown in Fig. 9B, however, this peak could not be found in $\mathrm{UV} / \mathrm{vis}$ absorption spectrum of R6G-containing aqueous micellar solution of $\mathrm{PEG}_{113}-b-\mathrm{PS}_{100}$ diblock copolymer 

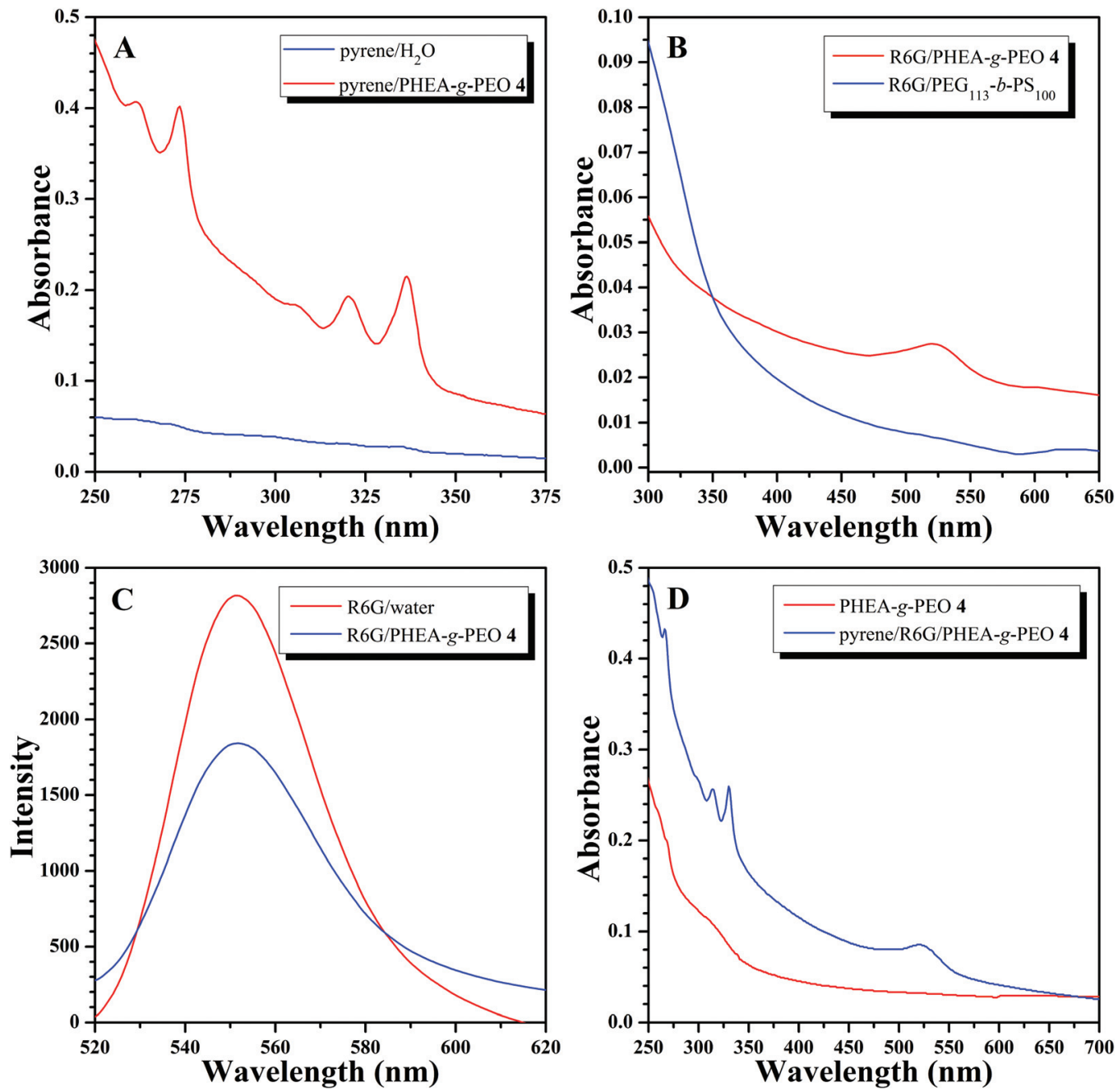

Fig. 9 (A) UV/vis absorption spectra of pyrene in water and aqueous micellar solution of PHEA-g-PEO 4. (B) UV/vis absorption spectra of R6G in aqueous micellar solutions of PHEA-g-PEO 4 and PEG 113 $-b-\mathrm{PS}_{100}$. (C) Fluorescence emission spectra of R6G in water and an aqueous micellar solution of PHEA-g-PEO 4. (D) UV/vis absorption spectra of pyrene and R6G in an aqueous micellar solution of PHEA-g-PEO 4, and the micellar solution of graft copolymer 4 for the control experiment.

(Fig. 9B), which formed common spherical micelles with an average hydrodynamic diameter of $73 \mathrm{~nm}$ in aqueous media. ${ }^{79}$ This fact obviously verified that the large compound micelles formed by copolymer 4 can capture R6G within the hydrophilic domains of the core of large compound micelles, ${ }^{81,82}$ while the common spherical micelles formed by $\mathrm{PEG}_{113}-b-\mathrm{PS}_{100}$ diblock copolymer cannot encapsulate $\mathrm{R} \mathrm{GG}^{78}$ It is well-recognized that the fluorescence intensity of R6G in aqueous micellar solution will be much lower than that of R6G in pure water solution. ${ }^{78,79}$ Fig. 9C shows that the fluorescence intensity of R6G-containing aqueous micellar solution of copolymer 4 is just $65 \%$ that of pure aqueous solution of R6G with the same apparent concentration of R6G, which clearly indicated the self-quenching effect of R6G in the micellar solution, that is, R6G was indeed located inside the micelles formed by copolymer $\mathbf{4}$, and not free in water. Moreover, both pyrene and R6G can be encapsulated by aqueous micellar solution of copolymer 4 simultaneously.
Both typical UV absorption peaks appeared at 332 (pyrene) and 522 (R6G) nm in UV/vis absorption spectrum of R6G/ pyrene-containing aqueous micellar solution of copolymer $\mathbf{4}$ (Fig. 9D), which were absent in UV/vis absorption spectrum of aqueous micellar solution of copolymer 4 (Fig. 9D), indicating the co-solubilization of R6G and pyrene model loading agents within the core of micelles formed by copolymer 4 . All these results demonstrated that large compound micelles formed by copolymer 4 can separately or simultaneously uptake hydrophobic and hydrophilic compounds, different from common spherical micelles, which was similar to the previous literature. $^{78}$

\section{Conclusions}

We have presented the detailed synthesis of PHEA-g-PEO well-defined graft copolymer with a narrow molecular weight 
distribution $\left(M_{\mathrm{w}} / M_{\mathrm{n}}=1.16\right)$ through sequential RAFT polymerization and ATNRC reaction via the grafting-onto strategy, using a Cl-containing HECPMA trifunctional monomer as starting material. The whole synthesis process avoided postpolymerization functionality transformation since the pendant - $\mathrm{OCOCH}\left(\mathrm{CH}_{3}\right) \mathrm{Cl}$ and hydroxyl groups of HECPMA acrylate monomer could remain inert during RAFT homopolymerization. With the successful preparation of PHECPMA homopolymer, the versatility of ATNRC can enable the substitution of PEO segments by other polymeric chains bearing TEMPO end functionality, which obviously paves a convenient way for developing new well-defined graft copolymers bearing PHEA backbone. The self-assembly behavior of PHEA- $g$-PEO graft copolymer in aqueous media was investigated by TEM, and large compound micelles with PEO as corona were formed in aqueous solution. In particular, the multicomponent structure of large compound micelles formed by PHEA- $g$-PEO graft copolymer could be used as a multicompartment delivery vehicle for the separate or simultaneous uptake of hydrophobic and hydrophilic compounds, which was verified to be able to separately or simultaneously package pyrene and R6G compounds in its different nanodomains.

\section{Acknowledgements}

The authors acknowledge the financial support from National Natural Science Foundation of China (21274162), Strategic Priority Research Program of Chinese Academy of Sciences (XDB20020000), and Shanghai Scientific and Technological Innovation Project (16JC1402500 and 16520710300).

\section{Notes and references}

1 J. Li, X. Chen and Y. C. Chang, Langmuir, 2005, 21, 95629567.

2 L. Hong, J. He, Y. Chen and T. Kakuchi, Polym. Chem., 2016, 7, 3599-3607.

3 J. S. Wang and K. Matyjaszewski, J. Am. Chem. Soc., 1995, 117, 5614-5615.

4 K. Matyjaszewski and J. H. Xia, Chem. Rev., 2001, 101, 2921-2990.

5 M. Ouchi, T. Terashima and M. Sawamoto, Chem. Rev., 2009, 109, 4963-5050.

6 K. Matyjaszewski, Macromolecules, 2012, 45, 4015-4039.

7 G. Moad, E. Rizzardo and S. H. Thang, Acc. Chem. Res., 2008, 41, 1133-1142.

8 G. Moad, E. Rizzardo and S. H. Thang, Polymer, 2008, 49, 1079-1131.

9 V. Percec, T. Guliashvili, J. S. Ladislaw, A. Wistrand, A. Stjerndahl, M. J. Sienkowska, M. J. Monteiro and S. Sahoo, J. Am. Chem. Soc., 2006, 128, 14156-14165.

10 S. R. Samanta, R. Cai and V. Percec, Polym. Chem., 2015, 6, 3259-3270.
11 X. Pang, L. Zhao, C. Feng, R. Wu, H. Ma and Z. Lin, Polym. Chem., 2013, 4, 2025-2032.

12 B. Mo, H. Liu, X. Zhou and Y. Zhao, Polym. Chem., 2015, 6, 3489-3501.

13 Q. Tang, J. Chen, Y. Zhao and K. Zhang, Polym. Chem., 2015, 6, 6659-6663.

14 N. Hadjichristidis, M. Pitsikalis, S. Pispas and H. Iatrou, Chem. Rev., 2001, 101, 3747-3792.

15 J. Burdynska, Y. Li, A. V. Aggarwal, S. Höger, S. S. Sheiko and K. Matyjaszewski, J. Am. Chem. Soc., 2014, 136, 1276212770 .

16 J. Teng and E. R. Zubarev, J. Am. Chem. Soc., 2003, 125, 11840-11841.

17 D. J. Siegwart, J. K. Oh and K. Matyjaszewski, Prog. Polym. Sci., 2012, 37, 18-37.

18 H. R. Culver, S. D. Steichen, M. Herrera-Alonso and N. A. Peppas, Langmuir, 2016, 32, 5629-5636.

19 L. Lempke, A. Ernst, F. Kahl, R. Weberskirch and N. Krause, Adv. Synth. Catal., 2016, 358, 1491-1499.

20 Y. Xia, B. D. Olsen, J. A. Kornfield and R. H. Grubbs, J. Am. Chem. Soc., 2009, 131, 18525-18532.

21 L. N. Gu, Z. Shen, S. Zhang, G. L. Lu, X. H. Zhang and X. Y. Huang, Macromolecules, 2007, 40, 4486-4493.

22 A. Cappelli, M. Paolino, G. Grisci, G. Giuliani, A. Donati, R. Mendichi, A. C. Boccia, F. Samperi, S. Battiato, E. Paccagnini, E. Giacomello, V. Sorrentino, M. Licciardi, G. Giammona and S. Vomero, Polym. Chem., 2011, 2, 25182527.

23 Y. G. Li, Y. Q. Zhang, D. Yang, Y. J. Li, J. H. Hu, C. Feng, S. J. Zhai, G. L. Lu and X. Y. Huang, Macromolecules, 2010, 43, 262-270.

24 H. F. Gao and K. Matyjaszewski, J. Am. Chem. Soc., 2007, 129, 6633-6639.

25 G. Cavallaro, M. Licciardi, M. D. Stefano, G. Pitarresi and G. Giammona, Macromolecules, 2009, 42, 3247-3257.

26 B. S. Sumerlin, D. Neugebauer and K. Matyjaszewski, Macromolecules, 2005, 38, 702-708.

27 C. Feng, Y. J. Li, D. Yang, J. H. Hu, X. H. Zhang and X. Y. Huang, Chem. Soc. Rev., 2011, 40, 1282-1295.

28 A. C. Engler, H. I. Lee and P. T. Hammond, Angew. Chem., Int. Ed., 2009, 48, 9334-9338.

29 H. C. Kolb, M. G. Finn and K. B. Sharpless, Angew. Chem., Int. Ed., 2001, 40, 2004-2021.

30 J. F. Lutz, Angew. Chem., Int. Ed., 2007, 46, 1018-1025.

31 R. K. Iha, K. L. Wooley, A. M. Nyström, D. J. Burke, M. J. Kade and C. Hawker, Chem. Rev., 2009, 109, 56205686.

32 T. P. Lodge, Macromolecules, 2009, 42, 3827-3829.

33 W. C. Lin, Q. Fu, Y. Zhang and J. L. Huang, Macromolecules, 2008, 41, 4127-4135.

34 Q. Fu, W. C. Lin and J. Huang, Macromolecules, 2008, 41, 2381-2387.

35 Y. Deng, S. Zhang, G. L. Lu and X. Y. Huang, Polym. Chem., 2013, 4, 1289-1299.

36 G. W. Wang and J. L. Huang, Polym. Chem., 2014, 5, 277-308. 
37 D. Yang, C. Feng and J. H. Hu, Polym. Chem., 2013, 4, 2384-2394.

38 Q. Fu, G. W. Wang, W. C. Lin and J. L. Huang, J. Polym. Sci., Part A: Polym. Chem., 2009, 47, 986-990.

39 R. M. Sun, G. W. Wang, C. Liu and J. L. Huang, J. Polym. Sci., Part A: Polym. Chem., 2009, 47, 1930-1938.

40 S. Sugihara, S. P. Armes and A. L. Lewis, Angew. Chem., Int. Ed., 2010, 49, 3500-3503.

41 J. Z. Du and S. P. Armes, J. Am. Chem. Soc., 2005, 127, 12800-12801.

42 S. Pioge, L. Fontaine, C. Gaillard, E. Nicol and S. Pascual, Macromolecules, 2009, 42, 4262-4272.

43 J. Zhu and R. C. Hayward, J. Am. Chem. Soc., 2008, 130, 7496-7502.

44 A. C. French, A. L. Thompson and B. G. Davis, Angew. Chem., Int. Ed., 2009, 48, 1248-1252.

45 Y. Akiyama, H. Otsuka, Y. Nagasaki, M. Kato and K. Kataoka, Bioconjugate Chem., 2000, 11, 947-950.

46 S. D. Xiong, L. Li, J. Jiang, L.-P. Tong, S. Wu, Z.-S. Xu and P. K. Chu, Biomaterials, 2010, 31, 2673-2685.

47 C. V. Bonduelle and E. R. Gillies, Macromolecules, 2010, 43, 9230-9233.

48 H. Yin, S. W. Kang and Y. H. Bae, Macromolecules, 2009, 42, 7456-7464.

49 G. Wanka, H. Hoffmann and W. Ulbricht, Macromolecules, 1994, 27, 4145-4159.

50 S. Boisse, J. Rieger, A. Di-Cicco, P. A. Albouy, C. Bui, M. H. Li and B. Charleux, Macromolecules, 2009, 42, 86888696.

51 Y. G. Li, M. Du, Y. J. Li, L. Sui, G. L. Lu and X. Y. Huang, J. Polym. Sci., Part A: Polym. Chem., 2012, 50, 4783-4789.

52 Y. G. Li, M. Du, Y. Q. Zhang, Y. J. Li, L. Sui, G. L. Lu and X. Y. Huang, J. Polym. Sci., Part A: Polym. Chem., 2012, 50, 1890-1899.

53 Y. G. Li, Y. Q. Zhang, S. J. Zhai, Y. Deng, H. M. Xiong, G. L. Lu and X. Y. Huang, J. Polym. Sci., Part A: Polym. Chem., 2011, 49, 23-34.

54 X. H. Zhang, Z. Shen, C. Feng, D. Yang, Y. G. Li, J. H. Hu, G. L. Lu and X. Y. Huang, Macromolecules, 2009, 42, 42494256.

55 S. Villarroya, J. Zhou, K. J. Thurecht and S. M. Howdle, Macromolecules, 2006, 39, 9080-9086.

56 Y. Cai, Y. Tang and S. P. Armes, Macromolecules, 2004, 37, 9728-9737.

57 J. N. Kizhakkedathu and D. E. Brooks, Macromolecules, 2003, 36, 591-598.

58 H. I. Lee, K. Matyjaszewski, S. Yu and S. S. Sheiko, Macromolecules, 2005, 38, 8264-8271.

59 J. V. M. Weaver, I. Bannister, K. L. Robinson, X. BoriesAzeau, S. P. Armes, M. Smallridge and P. McKenna, Macromolecules, 2004, 37, 2395-2403.
60 X. Y. Jiang, G. L. Lu, C. Feng and X. Y. Huang, Polym. Chem., 2014, 5, 4915-4925.

61 G. Moad, J. Chiefari, Y. K. Chong, J. Krstina, R. T. A. Mayadunne, A. Postma, E. Rizzardo and S. H. Thang, Polym. Int., 2000, 49, 993-1001.

62 K. Matyjaszewski, S. G. Gaynor and A. H. E. Muller, Macromolecules, 1997, 30, 7034-7041.

63 S. Pal, S. G. Roy and P. De, Polym. Chem., 2014, 5, 12751284.

64 M. Lejars, A. Margaillan and C. Bressy, Polym. Chem., 2013, 4, 3282-3292.

65 S. H. Wang, Q. X. Shen, M. H. Nawaz and W. A. Zhang, Polym. Chem., 2013, 4, 2151-2157.

66 S. Perrier, P. Takolpuckdee and C. A. Mars, Macromolecules, 2005, 38, 2033-2036.

67 S. Basu, D. R. Vutukuri, S. Shyamroy, B. S. Sandanraj and S. Thayumanavan, J. Am. Chem. Soc., 2004, 126, 9890-9891.

68 Q. Fu, Z. N. Zhang, W. C. Lin and J. L. Huang, Macromolecules, 2009, 42, 4381-4383.

69 Z. F. Jia, Q. Fu and J. L. Huang, Macromolecules, 2006, 39, 5190-5193.

70 D. Peng, X. H. Zhang and X. Y. Huang, Macromolecules, 2006, 39, 4945-4947.

71 N. V. Tsarevsky, S. A. Bencherif and K. Matyjaszewski, Macromolecules, 2007, 40, 4439-4445.

72 L. C. You, F. Z. Lu, Z. C. Li, W. Zhang and F. M. Li, Macromolecules, 2003, 36, 1-4.

73 P. S. Xu, H. D. Tang, S. Y. Li, J. Ren, E. V. Kirk, W. J. Murdoch, M. Radosz and Y. Q. Shen, Biomacromolecules, 2004, 5, 1736-1744.

74 G. M. Whitesides and B. Grzybowski, Science, 2002, 295, 2418-2421.

75 S. B. Clendenning, S. Fournier-Bidoz, A. Pietrangelo, G. C. Yang, S. J. Han, P. M. Brodersen, C. M. Yip, Z. H. Lu, G. A. Ozin and I. Manners, J. Mater. Chem., 2004, 14, 16861690.

76 L. F. Zhang and A. Eisenberg, J. Am. Chem. Soc., 1996, 118, 3168-3181.

77 C. Feng, G. L. Lu, Y. J. Li and X. Y. Huang, Langmuir, 2013, 29, 10922-10931.

78 B. B. Xu, G. X. Gu, C. Feng, X. Jiang, J. H. Hu, G. L. Lu, S. Zhang and X. Y. Huang, Polym. Chem., 2016, 7, 613624.

79 T. P. Lodge, A. Rasdal, Z. B. Li and M. A. Hillmyer, J. Am. Chem. Soc., 2005, 127, 17608-17609.

80 E. N. Savariar, S. V. Aathimanikandan and S. Thayumanavan, J. Am. Chem. Soc., 2006, 128, 16224-16230.

81 Y. R. Que, C. Feng, S. Zhang and X. Y. Huang, J. Phys. Chem. C, 2015, 119, 1960-1970.

82 H. M. Jung, K. E. Price and D. T. McQuade, J. Am. Chem. Soc., 2003, 125, 5351-5355. 